\title{
PRODUÇÃO CIENTÍFICA NACIONAL SOBRE INFECÇÃO HOSPITALAR E A CONTRIBUIÇÃO DA ENFERMAGEM: ONTEM, HOJE E PERSPECTIVAS
}

Rúbia Aparecida Lacerda ${ }^{1}$

Lacerda RA. Produção científica nacional sobre infecção hospitalar e a contribuição da enfermagem: ontem, hoje e perspectivas. Rev Latinoam Enfermagem 2002 janeiro-fevereiro; 10(1):55-63.

O artigo analisa a produção científica nacional sobre infecção hospitalar desde a década de 50, destacando a da enfermagem. 0 recurso teórico de análise foi sua contextualização com o desenvolvimento social do país e com as políticas de saúde introduzidas, permitindo constatar a estreita relação da evolução da infecção hospitalar no Brasil e da produção científica sobre esse tema com os modelos de assistência à saúde adotados. Discute a importância e os limites dessa produção científica e sua necessidade de inserir-se no campo mais amplo da qualidade da assistência em geral. Constata também que a produção da enfermagem já mostra evidências dessa tendência.

DESCRITORES: infecção hospitalar

\section{BRAZILIAN SCIENTIFIC PRODUCTION ON NOSOCOMIAL INFECTION AND NURSING CONTRIBUTION: PAST, PRESENTE AND PERSPECTIVES}

This article analyzes the Brazilian scientific production concerning nosocomial infection from 1950 to the present day and emphasizes the contribution from Nursing. The theoretical and analytical resource used was its contextualization with the country's social development and health policies, which enabled to demonstrate the close relationship between the development of nosocomial infection, the scientific production on such theme and the health care models adopted. The importance and limits of this scientific production are discussed as well as the need to include nosocomial infection in a larger field of care quality in general. The article also verified that the latest data on Nursing already show this tendency.

KEY WORDS: nosocomial infection

\section{PRODUCCIÓN CIENTÍFICA SOBRE INFECCIÓN HOSPITALAR EN EL BRASIL Y LA CONTRIBUCIÓN DE ENFERMERÍA: AYER, HOY Y PERSPECTIVAS}

Este articulo analiza la producción científica sobre lo que es la infección hospitalaria desde la década del 50, destacando la de enfermería. El recurso teórico de análisis fue su contextualización con el desarrollo social del país y con las políticas de salud introducidas, permitiendo constatar la estrecha relación de la evolución de la infección hospitalar en el Brasil y de la producción científica sobre este tema con los modelos de atención de salud adoptados. Discute la importancia y los límites de ésta producción científica y su necesidad de integrarse en el campo más amplio de la calidad de la atención en general. Constata también que la producción de enfermería ya muestra evidencias de ésta tendencia.

\section{DESCRIPTORES: infección hospitalaria}

\footnotetext{
${ }^{1}$ Enfermeiro, Professor Livre Docente da Escola de Enfermagem da Universidade de São Paulo, Endereço: Av. Dr. Enéas de Carvalho Aguiar, 419 - CEP 05403-000 - São Paulo - São Paulo - Brasil
} 


\section{INTRODUÇÃO}

Nesse artigo, buscou-se analisar a evolução da produção científica sobre infecção hospitalar $(\mathrm{IH})$ no Brasil, realizando-se uma compilação da bibliografia nacional, obtendo-se uma noção de sua evolução quantitativa e qualitativa, e a contribuição da enfermagem.

0 período abrange as décadas de 50 a 90 . Já na década de 40 inicia-se o reconhecimento internacional da IH "moderna": endógena e multi-resistente, através de uma pandemia por $\mathrm{S}$. aureus ${ }^{(1)}$. Tal período coincide com o pós-guerra e o desenvolvimento da tecnologia médico-hospitalar através de equipamentos $e$ medicamentos, como antibióticos e imunossupressores, favorecendo a evolução do modelo clínico, de características diagnóstica e terapêutica eminentemente invasivas, ou seja, quando se pensava ter superado a questão das infecções com 0 advento da penicilina, aliada à hemostasia e analgesia, e que as intervenções invasivas não teriam mais limites, aparece essa qualidade de infecção.

\section{ESTRATÉGIA METODOLÓGICA}

A produção científica foi obtida de periódicos nacionais, livros, teses e eventos, sendo muito volumosa, principalmente nas duas últimas décadas. 0 levantamento, apesar de minucioso, não abarca a sua totalidade, porém, como essa problemática é relativamente recente $\mathrm{e}$, pela facilidade atual da informática e do contato da autora com seus principais movimentos, pode-se afirmar que ele contém as principais informações de repercussão nacional sobre o tema.

As fontes de pesquisa foram os acervos das bibliotecas da BIREME, da Escola de Enfermagem da USP, Faculdade de Saúde Pública da USP, Ministério da Saúde ${ }^{(2)}$ e levantamentos bibliográficos presentes em estudos sobre o tema ${ }^{(3-6)}$.De 1980 até meados de 90, utilizou-se também o sistema LILACS. A partir de meados da década de 90, o levantamento referiu-se apenas à produção da enfermagem, aos arquivos da biblioteca da Escola de Enfermagem da USP. No total, foram obtidos cerca de 800 documentos, nas formas de títulos e resumos ${ }^{* *}$

A produção nas décadas de 50 e 60 é pífia. Na de 70 ela cresce consideravelmente e atinge seu ápice na de 80 . Uma das causas é que nas duas primeiras décadas os veículos de publicação eram poucos e não havia sistema informatizado de busca. Mas, a causa principal é porque a IH só se torna uma preocupação emergente no país a partir da década de 80 .

O recurso teórico utilizado para a análise desses documentos foi sua contextualização com o desenvolvimento social do país e as políticas de saúde introduzidas. A identificação e a mobilização mais intensa para o controle de infecção hospitalar $(\mathrm{ClH})$ em âmbito internacional iniciam-se na década de 50 nos países desenvolvidos, evidenciando-se a $\mathrm{IH}$ endógena e multi-resistente. No Brasil, o reconhecimento generalizado dessa nova modalidade de $\mathrm{IH}$, assim como as demandas para o seu controle só vêm acontecer em meados da década de 70 , estando intimamente relacionada com o modo de desenvolvimento da sociedade brasileira e com as políticas adotadas para o setor saúde, portanto, não ocorrendo simultaneamente com os países da Europa e os E.U.A. Os períodos do estudo abrangem fases distintas do padrão de relação entre 0 Estado e a Sociedade, o que determina diferentes formas de políticas públicas de saúde; a partir de suas situações conjunturais, é possível caracterizá-los como segue.

\section{RESULTADOS}

\section{A DÉCADA DE 50:}

O momento histórico de desenvolvimento social e de assistência à saúde

A década de 50 a meados de 60 representam a fase final de uma política de saúde onde predominava a assistência preventiva. Há poucos hospitais, quase todos públicos e de Santas Casas de Misericórdia ${ }^{(7)}$.

A produção científica nacional sobre $\mathrm{HH}$

As publicações encontradas não apresentam o mesmo teor, tampouco estabelecem articulações e discussões mais amplas sobre IH e seu controle, conforme já vinham acontecendo nos países desenvolvidos, nesse período. Mas, a preocupação com a transmissão de doenças infecciosas no hospital já está presente, ainda que o termo infecção hospitalar não seja usado.

Escreve-se sobre infecção em setores, a resistência a antibióticos já é conhecida, assim como críticas à falta de critérios do seu uso, porém sem associação com infecção endógena:

"Ato cirúrgico e infecções pós-operatórias" (1959)

\footnotetext{
* aspas do autor

** Devido o limite de espaço, os títulos dessa produção que são apresentados no artigo foram selecionados a fim de representar as temáticas que predominaram nos períodos abordados, não correspondendo à sua representação quantitativa
} 
As preocupações com o seu controle voltam-se eminentemente para o ambiente e procedimentos de anti-sepsia, não constituindo resultados de pesquisas nacionais; discutem seus avanços e recomendações técnicas, muitas vezes, utilizando bibliografias internacionais:

"Ar condicionado nos hospitais" (1954)

"Escovação em cirurgia" (1956)

"O problema do lixo nos hospitais" (1959)

A produção científica de enfermagem

Poucas publicações são de enfermeiros, referindo-se a técnicas de limpeza, assepsia e esterilização:

"A importância da assepsia na sala de operações" (1958)

"Assepsia - esterilização" (1959)

\section{A DÉCADA DE 60:}

O momento histórico de desenvolvimento social e de assistência à saúde

O desenvolvimento econômico adotado até essa década industrialização pesada- e a conseqüente aceleração da urbanização determinou aumento da demanda por assistência médica, atendida até então de forma desigual pelos vários Institutos de Aposentadorias e Pensões. Com a ditadura militar, os institutos são unificados, criando o INPS. O modo de financiamento abriu possibilidades para a iniciativa privada, que começa a criar hospitais com verbas quase exclusivamente públicas. A tecnologia médica dos países desenvolvidos começa a ser introduzida no país. Iniciam-se os primeiros transplantes, com o uso cada vez mais intensivo de antibióticos e de imunossupressores ${ }^{(7-8)}$.

A produção científica nacional sobre $\mathrm{IH}$

A literatura nos anos 60 denota as tendências de sua evolução. Ela já é reconhecida entre os profissionais desde o início da década, mas o termo $\mathrm{IH}$ praticamente não é usado. Alguns estudos tomam essas infecções como preocupação geral, buscando sua compreensão:

"Infecção cruzada nos hospitais gerais" (1964)

"Controle de infecções no hospital" (1964)

O setor mais presente é o berçário, local onde não se realizam procedimentos eminentemente invasivos, mostrando sua alta possibilidade de transmissão cruzada.

"Controle dos berçários contra as infecções"(1961)
As $\mathrm{IH}$ endógenas estão largamente difundidas, principalmente as causadas por estafilococos e estreptococos, os mesmos que desencadearam as epidemias nos hospitais dos países desenvolvidos, a partir do final da década de 40.

"Estudo sobre estafilococcias...."(1961)

"Infecção estreptocócica em clínica" (1968)

O reconhecimento da resistência bacteriana está presente. Estudos e ensaios sobre o uso de antibióticos também aparecem:

"Resistência infecciosa a drogas em bactérias"(1968)

"Emprego clínico de nova penicilina nas infecções estafilocócicas" (1962)

Pesquisas buscam compreender as fontes dos microrganismos e os mecanismos de transmissão dessa modalidade de infecção:

"Portadores de estafilococos coagulase positivos nos hospitais do Rio de Janeiro" (1963)

Contudo, a concepção de sua ocorrência ainda é predominantemente ambiental e procedimental. 0 seu controle continua referindo-se à higiene, anti-sepsia, desinfecção e esterilização, áreas de risco, fluxo de pessoal e de material.

"Assepsia no centro cirúrgico" (1961)

"Infecções veiculadas pelo ar e seu controle no hospital" (1961)

"O emprego de desinfetantes no hospital" (1966)

A produção científica de enfermagem

A produção dos enfermeiros ainda é pequena em relação à produção geral. Raras vezes discutem a nova modalidade de $\mathrm{IH}$. Contribuem predominantemente com as concepções ambiental e procedimental, no que se refere a assepsia, esterilização e desinfecção:

"Esterilização do material usado em salas de operações"

"Métodos de esterilização" (1961)

"Contaminação das mãos na arrumação de cama" (1966)

A maioria das publicações não é produto de resultados de pesquisa nacional. As poucas identificadas estão sob o enfoque procedimental e ambiental:

"Estudo da ação do parafórmico nas bactérias em forma esporulada" (1968)

"Estudo das condições bacteriológicas de um hospital" (1968)

Há publicações sobre a problemática geral da $\mathrm{IH}$, porém sem designar esse termo:

"Infecção em berçário" (1964) 


\section{A DÉCADA DE 70}

O momento histórico de desenvolvimento social e de assistência à saúde

O país encontra-se em plena ditadura militar, período caracterizado pela expansão da economia ${ }^{(8)}$. 0 crescimento da industrialização e a conseqüente urbanização demandam acesso crescente à assistência à saúde. A resposta do governo foi a unificação da assistência previdenciária, através da criação do INPS e a uniformização dos benefícios, já na década anterior. Contudo, ao invés de resolver a situação, a uniformização dos benefícios acentuou o conflito e não significou melhoria da qualidade da assistência. Isso se deve ao rumo que essa política tomou, ao adotar o modelo de assistência predominantemente curativo, especializado e tecnicista, indicando 0 interesse do Estado em se articular com o capital internacional, consoante suas políticas de desenvolvimento, entre elas, a permissão de entrada de indústrias multinacionais. Na situação específica da saúde, ocorre a expansão das indústrias farmacêuticas e de equipamentos hospitalares ${ }^{(9)}$.

Uma condição para aderência a esse modelo foi a Reforma Universitária em 1968, essencialmente tecnicista e privatizante, repercutindo sobre o saber e 0 ato médico. A assistência previdenciária unificada viabiliza a expansão de cobertura, com prioridade de contratação de serviços de terceiros. Com isso, os hospitais privados proliferam, sem o concomitante controle de qualidade. Os fundos sociais financiam, a juros baixos, a criação e a remodelação dos hospitais, além de favorecer a importação de recursos tecnológicos ${ }^{(9)}$.

Assim, o país integra-se rapidamente aos centros mais desenvolvidos desse modelo de assistência à saúde, sem contudo ter resolvido suas questões preventivas. 0 país entra também, e definitivamente, na era das IH "modernas": endógenas e multiresistentes, tendo em vista as características dessa tecnologia, voltadas para intervenções diagnósticas e terapêuticas invasivas e Imunossupressoras.

Essa IH também apresenta a sua face "moderna-particular", pelo modo com que a assistência médica e sua tecnologia são introduzidas. Esse modo tem a ver com a sua distribuição, intensidade e forma de utilização: internações desnecessárias, multiplicação de atos médicos, preferências pelas intervenções mais caras, ênfase nos serviços cirúrgicos, deficiência de pessoal tecnicamente preparado. Como resultado, vamos conviver tanto com as infecções endógenas, quanto com as exógenas, que não são controladas ${ }^{(8)}$.

$\mathrm{O}$ aumento rápido e intenso da $\mathrm{IH}$ gera demandas para $\mathrm{O}$ seu controle, tanto pelos profissionais da saúde, detentores da assistência, quanto pela sociedade em geral. Mas, tais demandas não são convergentes. Uma tese de doutorado sobre o tema ${ }^{(6)}$ relata que as reportagens na mídia, nesse período, denota demandas da sociedade por acesso e melhoria de qualidade na assistência; já, entre os profissionais de saúde, a demanda se dá pela criação de um processo de trabalho específico para o controle de infecção hospitalar $(\mathrm{ClH})$, conforme se verá a seguir.

A produção científica nacional sobre $\mathrm{IH}$

A IH "moderna" entra definitivamente no cenário das publicações nacionais. Reconhece-se a sua multicausalidade, ou seja, não mais e apenas relacionada ao ambiente e a procedimentos, mas à susceptibilidade individual e à evolução do modelo clínico e sua incorporação de tecnologia. $\mathrm{O}$ termo $\mathrm{IH}$ e as publicações sobre a sua problemática geral intensificam-se:

"O problema da infecção no hospital" (1973)

"Fontes de infecção no hospital" (1972)

Escreve-se sobre a necessidade do $\mathrm{ClH}$ em todo o hospital e não apenas por setores:

"A coordenação de medidas preventivas contra as infecções hospitalares" (1972)

Surge a principal alternativa para controlar o problema de forma sistematizada, através da organização de Comissões de Controle de Infecção Hospitalar (CCIH):

"Infecção hospitalar: importância da comissão de controle"

"Comissão de controle de infecção hospitalar do Hospital e Maternidade São Luís" (1974)

O uso da epidemiologia como instrumento da $\mathrm{CClH}$ aparece apenas no final da década:

"Métodos epidemiológicos para o controle de infecções hospitalares" (1979)

Pela primeira vez, escreve-se sobre conseqüências mais ampliadas dessa ocorrência:

"Importância médico-social e econômica da infecção adquirida em hospital' (1973/74)

$\mathrm{O}$ amplo reconhecimento da nova qualidade da $\mathrm{IH}$ desencadeia variados temas de pesquisa: controle de antibióticos; avaliações clínicas e laboratoriais sobre resistência bacteriana; contaminação de veículos como soro, medicamentos, etc. ${ }^{(4)}$.

Estudos sobre $\mathrm{ClH}$ em setores ainda predominam e alargam-se para além dos berçários e centro cirúrgicos, como UTI, lactário, serviço de nutrição, lavanderia. Escreve-se pouco ainda sobre IH por "sítios" ou síndromes infecciosas, situação que se inverterá na década seguinte. 
$\mathrm{Na}$ esteira da criação de $\mathrm{CClH}$ publica-se, pela primeira vez, sobre a necessidade da enfermeira nessa comissão, reconhecendo-a inclusive como um dos seus agentes principais.

A produção científica de enfermagem

Essa produção também aumenta e diversifica-se. Discutese a problemática geral da IH e a organização de processo de trabalho para o seu controle recebe contribuição fundamental dos enfermeiros. Porém, isso só ocorre a partir de meados da década:

"Infecções hospitalares: retrospectiva e enfoque atual" (1976)

"Infecção hospitalar - comissão de controle, estrutura e organização" (1977)

"Enfermagem ajuda na implantação de controle de infecção hospitalar (1978)

Pesquisas pioneiras são realizadas, sob enfoques clínicobacteriológicos para avaliação de produtos e de métodos de antisepsia, desinfecção, etc.; em suma, de concepções ambiental e procedimental:

"Estudo bacteriológico da unidade do paciente no momento de internação" (1976)

"Contribuição para o estudo de colonização bacteriana aeróbia da pele e infecção pós-operatória..." (1972)

"Efeito do banho de imersão na incidência de germes ... no coto umbilical..." (1975)

Publicações sobre a atuação da enfermagem no $\mathrm{ClH}$ são numerosas, desde o início da década, ainda que não se tratem de pesquisas:

"Contribuição da enfermeira no controle de contaminação hospitalar" (1971)

"A enfermagem na profilaxia da infecção hospitalar" (1974)

Temáticas sobre $\mathrm{CIH}$ por sítios e em setores são encontradas em menor proporção:

"Infecção do paciente cirúrgico. Cuidados para sua prevenção" (1976)

"Controle das infecções em berçários"(1979)

0 volume maior de publicações continua se referindo ao ambiente e procedimentos, principalmente de assepsia e processamento de artigos médico-hospitalares, mantendo a sua tendência histórica de propiciar um ambiente hospitalar seguro para as intervenções:

"Descontaminação químico-microbiológica de ambientes hospitalares por meio de purificador iônico" (1972)

"Métodos físicos de uma central de esterilização" (1974)

\section{A DÉCADA DE 80}

O momento histórico de desenvolvimento social e de assistência à saúde

A IH "explode" na mídia no início da década, em tons catastróficos: "Pesquisador diz que infecção hospitalar mata 150 mil por ano"-Jornal do Brasil, 1981; "Infecção é a quarta causa de mortes no país, diz médico"-Folha de São Paulo, 1980 ${ }^{(4)}$.

Há uma constatação generalizada da gravidade do problema, com acusações dos vários setores da sociedade: usuários, profissionais da saúde, donos de hospitais, etc. Justificativas apresentam-se como defesa, reduzindo o problema a um fenômeno universal, uma vez que existente em todos os hospitais do mundo ou como conseqüência indesejável da evolução do modelo clínico; outras, reconhecem sua relação com a péssima qualidade de assistência prestada pelos hospitais. As demandas para providências intensificam- se ainda mais com a repercussão da morte do presidente Tancredo Neves, agravada pela IH, em $1985^{(10)}$.

No contexto social, essa década significa de um lado, a abertura política e a conquista de vários direitos sociais, culminando com a Constituição de 88. De outro, há uma crise econômica sem precedentes. No âmbito da assistência à saúde, o modelo adotado contribui para que a crise da previdência atinja seu clímax, sem capacidade de financiar a grande maioria dos atendimentos. Assim, explode também a assistência pela medicina de grupo ${ }^{(11)}$.

A $\mathrm{IH}$ aumenta em quantidade e gravidade. As denúncias não vêm sozinhas, mas com outras ocorrências devidas à péssima qualidade da assistência prestada, além da falta e desigualdade de acesso. Contudo, as ações governamentais atendem a demanda dos profissionais de saúde, através de um processo de trabalho especificamente dirigido ao $\mathrm{CIH}$, que já vinha sendo apresentado nas suas produções científicas: a CCIH. Ainda que não se negasse a estreita relação da $\mathrm{IH}$ com o modelo de assistência predominante e sua qualidade, o reconhecimento para seu controle através de uma melhor qualificação geral dessa assistência só vem generalizar-se a partir de meados da década de $90^{(10)}$.

A produção científica nacional sobre $\mathrm{IH}$

Publicações sobre essa problemática aparecem de forma mais intensa, tipo denúncias:

"Combate sem armas às infecções hospitalares" (1981)

"Infecção hospitalar: a tragédia no Brasil" (1985)

A necessidade de organização de processos de trabalho de $\mathrm{ClH}$ torna-se expressiva. Há praticamente consenso entre os profissionais que já atuavam isoladamente com essa questão, sobre 
como deve ser esse processo de trabalho, através da criação de $\mathrm{CClH}$ :

"Comissão de controle de infecção hospitalar: objetivos e fundamentos" (1983)

Estudos bacteriológicos e de resistência a antibióticos intensificam-se, assim como infecções por sítios, síndromes e especialidades, além de setores. O microorganismo já não é o maior "vilão", mas as condições que propiciam sua propagação e resistência:

"Pneumonias hospitalares" (1986)

"Infecções urinárias no paciente com cateterismo prolongado" (1986)

"Transfusão de sangue contaminado" (1983)

"Bacteremias hospitalares" (1985)

O reconhecimento da multicausalidade de sua ocorrência detona estudos sobre fatores de risco e susceptibilidade:

"Nutrição x infecção hospitalar: um alerta para a equipe de saúde" (1985)

"Tricotomia: um fator determinante de infecção do sítio cirúrgico" (1987)

"Análise dos fatores relacionados à incidência de infecções urinárias em pacientes com câncer" (1983)

A vigilância epidemiológica, como instrumento da $\mathrm{CClH}$, é objeto de pesquisa:

"Sistema de vigilância epidemiológica de infecções hospitalares" (1982)

"Infecção hospitalar: comparação entre dois métodos de vigilância epidemiológica" (1989)

Tal instrumento favorece a busca de casos de IH, dimensiona a elaboração de indicadores epidemiológicos de incidência e prevalência e favorece pesquisas comparativas:

"Incidência de infecção hospitalar no hospital AMICO" (1985)

"Estudo comparativo da incidência de infecção do trato urinários em pacientes com sonda vesical de demora ligada a sistema de coleta aberto e fechado" (1987)

Publicações sobre controle ambiental e procedimental continuam e intensificam-se, agora, não mais realizadas predominantemente pela enfermagem, principalmente no que diz respeito a avaliações laboratoriais de produtos esterilizantes, desinfetantes e anti-sépticos:

"Avaliação da ação antimicrobiana de dois desinfetantes hospitalares" (1989)

"Coeficiente fenólico na avaliação microbiológica de desinfetantes de uso hospitalar e doméstico" (1989)

É nessa década que também surgem as principais ações governamentais para validação e padronização de produtos e processos desinfetantes, anti-sépticos e esterilizantes. As pesquisas nacionais e o maior intercâmbio com centros internacionais favorecem melhor conhecimento de fontes de microrganismos, fatores de risco e formas de transmissão, permitindo discutir mitos e rituais de práticas tradicionais e novas tecnologias. A enfermagem produz contribuição importante, inclusive através de pesquisas, como se verá a seguir.

A produção científica de enfermagem

Pela primeira vez, a enfermagem já não publica predominantemente aspectos relacionados a procedimentos de limpeza, desinfecção e esterilização de ambiente e artigos.

Levantamento bibliográfico abrangendo o período de 1980 a $1987^{(5)}$ mostra a distribuição da produção de enfermagem referente ao $\mathrm{CIH}$ : procedimentos técnicos: $37,37 \%$; infra-estrutura para o $\mathrm{CIH}$ : 22,22\%; CCIH: 15,15; estudos bacteriológicos/ epidemiológicos: 15,15\%; anti-sépticos, desinfetantes, esterilizantes: 10,10\%.

Note-se que somente na década de 90 será amplamente reconhecida a importância de estudos de procedimentos técnicos como uma das principais alternativas para o $\mathrm{ClH}$, ou seja, a busca de qualificação da assistência direta, incorporando assim, o CIH ao controle mais amplo da qualidade. Isso, porque a ênfase na vigilância epidemiológica e na realização de indicadores epidemiológicos, além das inúmeras tentativas de destruir microrganismos e utilizar barreiras microbiológicas, não se mostrarão suficientes para controlar a $\mathrm{IH}$.

Dentre as publicações relacionadas à infra-estrutura para o $\mathrm{ClH}$ e organização de $\mathrm{CClH}$, várias referem-se à atuação do enfermeiro nesse processo de trabalho, reforçada pelo reconhecimento dessa categoria como seu agente fundamental e institucionalizado, inclusive, sob ações governamentais ${ }^{(2,12-13)}$ :

"Atividades das enfermeiras de comissões de controle de infeção hospitalar de hospitais ... de São Paulo" (1987)

"Atuação da enfermeira na comissão de controle de infecção hospitalar" (1985)

"O trabalho da enfermeira de controle de infecção hospitalar"

Pesquisas também buscam reconhecer as dificuldades para a implantação de $\mathrm{CCIH}$ :

"Infecção hospitalar no Brasil: um enfoque sobre o seu controle" (1987)

Vários estudos sobre sistemas de vigilância são realizados por enfermeiros, que participam ativamente no aprimoramento de métodos de coleta de dados de $\mathrm{IH}$ :

"Infecção hospitalar em berçário ...: estudo comparativo entre dois métodos de vigilância epidemiológica" (1986)

"Sistema de vigilância epidemiológica de infecções hospitalares" (1982) 
"Método de controle de infecção hospitalar orientado por problemas" (1986)

Pesquisas sobre métodos de esterilização, desinfecção e anti-sepsia, assim como clínico-bacteriológicas continuam sendo realizadas, destacando-se o aperfeiçoamento metodológico e melhor conhecimento em microbiologia, determinando maior segurança para comprovação da eficácia de processos e produtos. De outro modo, ora reconhecendo certas práticas tradicionais como desnecessárias ao $\mathrm{ClH}$, ora demandando introdução de novas tecnologias, ou demonstrando sua ineficácia. Entre eles:

"Anti-sépticos e desinfetantes: deterioração e contaminação" (1982)

"Avaliação da atividade esterilizante do paraformaldeído" (1989)

"Estudo comparativo da incidência de infecção do trato urinário em pacientes com sonda vesical de demora ligada a sistema de coleta aberto e fechado" (1987)

"Sala de operação contaminada: um momento de reflexão"

\section{A DÉCADA DE 90}

O momento histórico de desenvolvimento social e de assistência à saúde

Essa década vivencia as tentativas de implementar 0 sistema de saúde vigente (SUS), com suas premissas de universalização, hierarquização, eqüidade e regionalização ${ }^{(13)}$. Contudo, o modelo de desenvolvimento econômico adotado, neoliberalismo globalizado em um país periférico, com enorme dependência do capital externo, aumenta o endividamento, prejudica a produção nacional, com desemprego sem precedentes. Tal situação tem levado a cortes nos gastos sociais e necessariamente influenciam a implementação de políticas sociais legalmente conquistadas. $\mathrm{Na}$ prática, no que se refere à assistência à saúde, assiste-se a migração para a medicina de grupo da parcela da população que pode pagar planos privados e o SUS, ao contrário de suas premissas, corre 0 risco de se transformar em um modelo excludente ${ }^{(14)}$.

A produção científica nacional sobre $\mathrm{IH}$

Embora não tenha sido realizado um levantamento detalhado da produção científica de toda a década de 90,0 acompanhamento dos eventos científicos permite reconhecer duas tendências. Na primeira metade da década, $0 \mathrm{CIH}$ através de $\mathrm{CCIH}$, já estando amplamente divulgado e instituído, as publicações sobre esse processo de trabalho esmorecem. A produção volta-se para 0 aperfeiçoamento e a sofisticação dos métodos de coleta de dados de $\mathrm{IH}$ :

"Vigilância epidemiológica das infecções hospitalares na prática diária (ensaios)" (1993)

"Componentes NNISS" (1995)

Na prática, contudo e, apesar de toda a mobilização dos profissionais de $\mathrm{ClH}$ e das ações governamentais específicas através de legislações, campanhas, cursos e treinamentos, a própria Coordenadoria de CIH do Ministério da Saúde reconhece, em 1993, a pouca efetividade, estimando que apenas $10 \%$ dos hospitais tenham criado $\mathrm{CCIH}^{(15)}$.

Apesar dessa realidade, poucos estudos questionam esse processo de trabalho dominante. Um deles, critica a atomização do $\mathrm{ClH}$ através da vigilância epidemiológica, ocupando quase todo 0 tempo da enfermeira na coleta de dados e elaboração de indicadores de $\mathrm{IH}$. Também questiona a burocratização da $\mathrm{CCIH}$ e sua eficácia para controlar a $\mathrm{IH}$ :

"Infecções hospitalares no Brasil: ações governamentais para o controle de infecção hospitalar enquanto expressão de políticas sociais na área da saúde" (1995)

Na contramão da situação real e, na esteira do movimento de qualidade ainda incipiente no início da década, publicações chegam mesmo a divulgar que o $\mathrm{ClH}$ é o "paradigma" para o controle de qualidade na assistência à saúde, ou seja, reduzindo a qualidade à forma de processo de $\mathrm{ClH}$. É o caso do manual sobre acreditação de hospitais editado pela Organização Panamericana de Saúde e a Federação Latinoamericana de Hospitais, onde se observa que os indicadores epidemiológicos atomizam-se antes na estrutura e na organização dos serviços, do que nos processos ${ }^{(16)}$. Nesse caminho, desenvolve-se e divulga-se também a ciência da epidemiologia hospitalar.

A nova Portaria 2616/98, apesar de reconhecer que o $\mathrm{ClH}$ implica práticas mais abrangentes, inseridas no contexto geral da qualidade da assistência, reedita, ainda que mais atualizado, o mesmo processo de trabalho de $\mathrm{ClH}^{(13)}$.

Enquanto isso, as principais conquistas no $\mathrm{ClH}$ evidenciamse em estudos experimentais controlados sobre microrganismos e sua resistência, fontes e modos de transmissão, fatores de risco, além dos procedimentos técnicos, esses últimos, com participação ativa da enfermagem.

"Resistência a drogas em cepas bacterianas de pacientes de serviços hospitalares..."(1991)

"Buscando compreender a infecção hospitalar no paciente cirúrgico" (1992)

"Uso de propés no controle da contaminação do piso da sala de operações"(1991)

A importância de estudos sobre procedimentos técnicos 
só vem acontecer, com mais intensidade, a partir de meados da década de 90 , coincidindo com uma abordagem mais ampla sobre qualidade da assistência, coincidindo com autores que reconhecem a necessidade de se avaliar a assistência não somente referindo-se à sua estrutura e existência de serviços, mas às condições de realização dos procedimentos de assistência, isto é, aos processos ${ }^{(17)}$.

Ao mesmo tempo, o advento da AIDS, das Hepatites B e C e o recrudescimento da tuberculose detonam o reconhecimento de uma outra modalidade de $\mathrm{IH}$ : a ocupacional, que passa a dominar 0 cenário das preocupações de transmissão de infecção.

As medidas de controle, contudo, apresentam-se sob uma visão reduzida dessa problemática, publicando soluções tipo "receitas" generalizadas e desconsiderando, na maioria das vezes, as condições específicas em que os procedimentos são realizados. Da mesma forma, reduzindo as causas dos problemas de adesão. Tratam-se de alternativas oriundas predominantemente do Centro de Controle e Prevenção de Doenças (C.D.C) dos E.U.A. São os casos dos guidelines para controle das infecções por sítio, as precauções universais, etc.

Publicações nacionais acompanham tais concepções, buscando compreender as resistências à adesão:

"Riscos de infecção pelo vírus da imunodeficiência humana em profissionais de sáude"(1992)

Mas, pesquisas nacionais, que mostram caminhos próprios, continuam sendo realizadas e referem-se principalmente à validação de processos (esterilização, desinfecção, controle de ambiente, componentes de paramentação, embalagens de artigos, reutilização de descartáveis, etc.) e avaliação de procedimentos, principalmente pela enfermagem, conforme segue.

A produção científica de enfermagem

Assim como na produção geral, a de enfermagem, sobre organização de $\mathrm{CClH}$, vigilância epidemiológica e papel da enfermeira de $\mathrm{ClH}$ perdem o fôlego. Tal fato pode ser atribuído a duas causas. Uma delas, é que o $\mathrm{ClH}$ através de um processo de trabalho já bastante divulgado e sedimentado não demanda tanto a continuidade de estudos. Outra, refere-se, provavelmente, à própria perda da expressão do enfermeiro como um dos agentes principais da $\mathrm{CClH}$. A repercussão política e econômica da $\mathrm{IH}$ promove disputas de interesses e de representações, colocando em cena novos agentes, principalmente, os médicos infectologistas que, apesar de não estarem legalmente consolidados por legislação, atualmente dominam esse processo de trabalho, ficando o enfermeiro, em muitos casos, meramente coletando dados e elaborando indicadores de $\mathrm{IH}$. Enquanto isso acontece na prática, a produção científica da enfermagem começa a abordar novos temas, como a preocupação com o ensino de $\mathrm{IH}$ :

"O enfermeiro e a IH: um estudo sobre sua formação e atuação" (1997)

Estudos bacteriológicos continuam:

"Manutenção de um ambiente hospitalar biologicamente seguro: avaliação microbiológica dos leitos de um hospital geral antes e após a limpeza terminal" (1998)

Procedimentos técnicos e o controle de processos estão mais presentes e consistentes:

"Avaliação da adequação da paramentação cirúrgica durante cirurgias"(1998)

"Avaliação do ambiente de centro cirúrgico"(1998)

"Estudo sobre a eficácia do método de esterilização pelo calor seco, usando o forno de Pasteur- estufa" (1990)

Aparece também um estudo que busca aproximar $0 \mathrm{ClH}$ ao controle geral de qualidade na assistência, assim como acessar a responsabilidade de setores extra-hospitalares:

"Vigilância sanitária no $\mathrm{ClH}$ : do diagnóstico situacional à validação de estratégias de controle" (1998)

As publicações sobre a problemática e riscos de infecção ocupacional aumentam:

"Trabalhador de enfermagem na unidade de centro de material e os acidentes de trabalho"(1997)

"Adesão às precauções universais: uma análise do comportamento da equipe de enfermagem"(1995)

"Equipe de enfermagem: aceitação e uso das precauções universais"(1997).

\section{CONSIDERAÇÕES FINAIS}

A evolução da produção científica de $\mathrm{IH}$ permite observar sua relação estreita com o modelo de assistência dominante e a introdução de sua tecnologia, distribuída de formas diversa e desigual. Portanto, já se faz eminente o reconhecimento da problemática da IH não mais de forma isolada, mas contextualizada à qualidade da assistência à saúde de uma forma geral.

A inserção da produção científica sobre $\mathrm{ClH}$ nesse contexto mais ampliado pode ocorrer em três níveis: 1) na qualificação da assistência hospitalar em geral; 2) na elaboração de políticas de saúde, que se refiram a modelos e modos de produção dessa assistência; 3) na responsabilização do $\mathrm{ClH}$ a setores intra e extrahospitalares, além da $\mathrm{CClH}$.

Sua inserção na qualidade da assistência precisa considerar não somente a estrutura e a organização dos serviços, mas também sua distribuição e modo de utilização, assim como a realização dos 
processos de assistência. Nesses últimos, a participação do $\mathrm{CIH}$ dáse predominantemente através da qualificação dos procedimentos técnicos e reorganização dos processos de assistência direta, que incluem não somente equipamentos, mas também 0 redimensionamento quanti-qualitativo de recursos humanos e novas metodologias de trabalho, que resultem em melhores condições para sua efetivação.

Por sua vez, tal qualificação necessita de etapas básicas, decorrentes de pesquisas sobre a pertinência dos próprios procedimentos para o $\mathrm{ClH}$, entre eles, compatibilidade de uso de

\section{REFERÊNCIAS BIBLIOGRÁFICAS}

1. Grazebrook J. Counting the cost of infection. Nurs Times 1986; 82(6):24-6.

2. Ministério da Saúde (BR). Manual de controle de infecção hospitalar. Brasília (DF): Centro de Documentação do Ministério da Saúde; 1985. 3. Lacerda RA. Atividades das enfermeiras de comissões de controle de infecção hospitalar de hospitais do município de São Paulo. [dissertação]. São Paulo (SP): Escola de Enfermagem/USP; 1987.

4. Lacerda RA. Infecções hospitalares no Brasil. Ações governamentais para o seu controle enquanto expressão de políticas sociais na área da saúde. [tese]. São Paulo(SP): Escola de Enfermagem/USP; 1995.

5. Moriya TM, Pereira MS, Gir E. Pesquisas, conferências e artigos em infecção hospitalar: aspectos abordados pelos enfermeiros. Rev Esc Enfermagem USP 1991; 25(1):29-40.

6. Zanon U, Neves J. Infecções hospitalares. Prevenção, diagnóstico e tratamento. Rio de Janeiro (RJ): MEDSI; 1987.

7. Braga JC de Paula SG de. Saúde e previdência. Estudos de política social. São Paulo (SP): CEBES/HUCITEC; 1981.

8. Luz MT. As instituições médicas no Brasil. Instituições e estratégia de hegemonia. Rio de Janeiro (RJ): GRAAL, 1979. barreiras microbiológicas, uso de produtos químicos, processamento de materiais, adequação de ambiente, etc. Resultados esses, que só podem ser obtidos pela continuidade de pesquisas aplicadas e experimentais que evidenciem mitos e rituais ou que detectem novas necessidades ainda não reveladas.

Mas, se a realidade da produção científica de enfermagem já mostra tais tendências, a prática do $\mathrm{ClH}$ pelo enfermeiro ainda circunscreve-se à $\mathrm{CCIH}$. Caminhos esses que a própria produção científica, dessa vez, através de políticas e recursos teóricos críticos, deve tentar aproximar.

9. Oliveira A, Teixeira SMF. (Im)previdência social. 60 anos de história da previdência no Brasil. 2.ed. Rio de Janeiro (RJ): Vozes-Abrasco; 1989.

10. Lacerda RA, Jouclas VMG, Egry EY. A face iatrogênica do hospital. As demandas para o controle de infecção hospitalar. São Paulo(SP): Atheneu Editora São Paulo; 1996.

11. Fiori JL, Kornis GEM. Além da queda: economia e política numa década enviesada. In: Guimarães R, Tavares R, organizadores. Saúde e sociedade no Brasil - Anos 80. Rio de Janeiro (RJ): Relume-Dumará; 1994.

12. Ministério da Saúde (BR). Portaria n. 930 de 27 de agosto de 1992. Brasília (DF): Ministério da Saúde; 1992.

13. Ministério da Saúde (BR). Portaria n. 2616 de 12 de maio de 1998. Brasília (DF): Ministério da Saúde; 1998.

14. Faveret P Filho, Oliveira PJ de. A universalização excludente: reflexões sobre as tendências do sistema de saúde. Plan Pol Públ 1990; (3):139-62.

15. Coordenação de Controle de Infecção Hospitalar. Editorial. Bol Inf 1993; 1(1):1.

16. Organización Panamericana de Salud/ Federación Latinoamericana de Hospitales. La garantía de calidad. Accreditación de hospitales para America Latina y el Caribe. Washington (DC); 1991. 17. Malik AM. Qualidade em serviços de saúde nos setores públicos e privado. Cad FUNDAP 1996;7-24. 